\title{
Variation in the Interleukin-6 Gene Is Associated with Impaired Cognitive Development in Children Born Prematurely: A Preliminary Study
}

\author{
DAVID HARDING, DAVID BRULL, STEVE E. HUMPHRIES, ANDREW WHITELAW, \\ HUGH MONTGOMERY, AND NEIL MARLOW \\ Department of Child Health [D.H.], University of Bristol, Bristol BS2 8EG, UK, Division of \\ Cardiovascular Genetics [D.B., S.E.H., H.M.], University College London, London WC1E 6JJ, UK, \\ Neonatal Intensive Care Unit [A.W.], University of Bristol Medical School, Southmead Hospital, Bristol \\ BS10 5NB, UK, School of Human Development [N.M.], University of Nottingham, Nottingham NG 7 2UH, UK
}

\begin{abstract}
ABST
The pro-inflammatory cytokine IL-6 may be neurocytopatho-
genic, and elevated levels are associated with impaired neuro-
logical outcome among children born prematurely. However, the
precise mechanisms underlying this association remain unclear.
The rare C (rather than G) variant at position -572 in the IL-6
gene is associated with an increased IL-6 synthetic response. If
IL-6 mediates cerebral injury, we would anticipate the $-572 \mathrm{C}$
allele to be associated with impaired childhood development. We
have examined this hypothesis, studying 113 Caucasian children
born at $\leq 32$ wk gestation. Cognitive and motor functions were
assessed using the Griffiths Developmental Scales at 2 y and
British Ability Scales (2nd Ed.) and the ABC Movement Score at
$51 / 2$ y. Performance (median, interquartile range) in all three
scales was worse in the 10 carriers of the C allele than for those
with GG genotype: Griffiths Developmental Quotient: C allele,
\end{abstract}
92.4 (89.9-96.6) versus CG 100.9 (96.7-104.8), $p=0.002$; General Cognitive Ability: C allele, 88.0 (80.3-102.8) versus GG 103.0 (92.0-112.0), $p=0.037$; Movement ABC score: $\mathrm{C}$ allele $8.3(6.6-20.3)$ versus GG $4.0(1.0-9.5), p=0.081$. The presence of the rare $(\geq 1)$ IL- $6-572 \mathrm{C}$-allele $(\mathrm{CC}+\mathrm{GC}$ genotypes $)$ is associated with impaired cognitive development among children born before $32 \mathrm{wk}$ gestation. These data support a role for IL-6 in the genesis of neurologic impairment in such children. (Pediatr Res 58: 117-120, 2005)

\section{Abbreviations \\ DQ, Griffiths developmental quotient \\ GCA, general cognitive ability, British Ability Scales, 2nd Ed. WMD, white matter damage}

Disability is common among children born prematurely and is inversely related to gestational age at birth. As many as one half of those surviving after birth at $25 \mathrm{wk}$ gestational age or less have a severe disability at $21 / 2$ years of age, $50 \%$ of these being severe (1). Even those seemingly unaffected early on may demonstrate a range of motor, cognitive, behavioral, psychological, emotional, and educational deficits later in childhood (2-4). To date, a series of risk factors for such cognitive impairment (e.g. birth weight, chronic lung disease, and social factors) have been identified, although the biologic transduction mechanisms that result in cerebral injury remain occult (5).

The pro-inflammatory cytokine IL-6 may be one such biologic mediator. Perinatal concentrations of the pro-inflammatory cyto-

Received September 22, 2004; accepted November 9, 2004.

Correspondence: David Harding, Ph.D., Department of Child Health, St. Michael's Hospital, Bristol, BS82JZ, UK; e-mail: david.harding@bristol.ac.uk

This research was supported by awards from The Southmead Hospital Research Foundation to A.W. and D.H, and The British Heart Foundation (grants RG200015, SP98003, FS01XXX to S.H.E., H.M., and S.D.). The original APIP study was supported by Action Research (grant to N.M.).

DOI: 10.1203/01.PDR.0000163523.49021.53 kines such as IL-6 correlate directly with the development of periventricular WMD and subsequent neurologic deficit (6-10). WMD, in turn, may impair gray matter development throughout childhood $(11,12)$ and is perhaps responsible for some of the developmental deficits observed in children after premature birth. Correlating structural brain abnormality with specific functional deficits has proved difficult, however (13).

It remains unclear as to whether the association of elevated IL-6 levels with cerebral injury is innocent or causal. A genetic strategy of investigation may help elucidate the pathways that cause such injury: the association of a functional variant in the IL-6 gene with impaired neurological outcome would offer substantial evidence of causality. A candidate gene association study of this variety has advantages in the assessment of cytokine pathogenicity, where levels fluctuate rapidly and wildly, where total chronic burden of exposure cannot be measured, and where tissue generation may be more important than circulating levels themselves (14). Such a genetic variant does exist, which is applicable to such a study: a G/C substitution has been identified at position -572 in the IL-6 
gene- the rare $\mathrm{C}$ allele being associated with a higher IL-6 synthetic response (14).

If IL-6 plays a causal role in mediating cerebral injury and cognitive developmental progress after preterm birth, the C allele should be associated with such cognitive impairment. We have performed a pilot study to examine this hypothesis, using a well-defined cohort of preterm infants (15) with structured neurodevelopmental follow-up to $51 / 2$ y of age.

\section{METHODS}

Patients and developmental assessment. The study was approved by the ethical committees of Southmead Hospital and United Bristol Health Care Trust. Parental consent was obtained for participation in neurodevelopmental follow-up (15). Consent was not required for the genetic component of this study, as all personal information was held separately from the genetic information and patients were identified solely by study codes. The patients ( $\leq 32$ wk gestation, Caucasian) participated in a population-based developmental outcome study, the Avon Premature Infant Project (APIP) (15). Patients were prospectively recruited to a randomized controlled trial of Portage (an early education programme focused on the child) or social support (parent adviser scheme focused on the mother) intervention started at discharge and continued for up to $2 \mathrm{y}$, as previously described (15). Patients who were followed up at 2 and $5.5 \mathrm{y}$ were identified and Guthrie spots located where possible. Genotypes were successfully determined in 113 patients (below), representing $37 \%$ of the original APIP population $(n=308)$ and $60 \%$ of all infants followed up to $5.5 \mathrm{y}(n=187)$.

Cognitive and motor functions were assessed using the Griffiths Developmental Scales at $2 \mathrm{y}$ and British Ability Scales (2nd Ed.) (BAS) and the ABC Movement Score at 51/2 y. The Griffiths Mental Development Scales, used to assess motor and cognitive performance, was performed at 2 y corrected age (16). The Griffiths scales comprise five subscales, including personal and social, hearing and speech, locomotor, eye hand co-ordination, and performance domains, from which is derived an overall developmental quotient (DQ). A lower Griffiths DQ reflects a poorer neuro-developmental performance. A score of $70(-2 \mathrm{SD})$ would indicate severe disability instead of the conventional $55(-3 \mathrm{SD})$ due to secular drifts in population scores that have resulted in a higher population mean. Cognitive developmental progress at $5.5 \mathrm{y}$ of age was assessed using the BAS (17). The BAS computes GCA together with visuospatial, verbal, and nonverbal subscales. The GCA is a developmental quotient equivalent to an IQ estimate, normalized at 100 $(\mathrm{SD} \pm 15)$ in which a lower score again indicates poorer conceptual ability. The Movement $\mathrm{ABC}$ scales (18) assesses manual dexterity, ball skills, and balance over 10 tests. Scores of each component are summed to produce a score ranging from 0 to 40, with high scores indicating more impaired motor skills and scores close to 0 normal skills. A psychologist performed the Griffiths Scales of Mental Development, a second psychologist performed the BAS, and a research nurse the Movement ABC tests. These assessments were blind to the child's neonatal course and progress.

Cranial injury. Cranial ultrasound was performed on the day of birth, and then at least weekly until discharge. Images were reviewed prospectively (N.M.). Hemorrhagic ultrasound findings were classified as subependymal, intraventricular, or intraparenchymal, intraventricular hemorrhage being graded as small or large (the latter where the clot distended the lateral ventricle). Severe hemorrhage was defined as a large intraventricular hemorrhage or an intraparenchymal hemorrhage. Cystic periventricular leukomalacia was defined as echo-lucent cysts of $\geq 2 \mathrm{~mm}$ diameter in the periventricular white matter; ventriculomegaly was present if the ventricular size on the last scan was $>97^{\text {th }}$ percentile (19). No children developed progressive posthemorrhagic hydrocephalus in this cohort. For analysis, cystic periventricular leukomalacia and ventriculomegaly were combined as PVL consistent with the view that most ventricular enlargement is due to WMD, either focal (cystic) or diffuse (20-22). The worst grade of findings was used in all cases.

Genotyping. DNA was extracted from routinely stored Guthrie cards and IL-6 genotypes determined as previously described (14) using the primers (5'-GGAGACGCCTTG-AAGTAACTGC-3' and 5'-GAGTTTCCTCTGACTCCATC-GCAG-3') to generate a 163 bp PCR fragment. Genotypes were resolved by using restriction endonuclease digestion. The rare $-572 \mathrm{C}$ allele lacks the digestion site for MbI1. The size of the digestion products was determined by using microtiter array diagonal gel electrophoresis by two independent observers blinded to clinical details.

Statistical analysis. Outcomes were examined for association with IL-6 promoter polymorphism genotypes $-572 \mathrm{CC}+\mathrm{CG}$ compared with $\mathrm{GG}$, using SPSS for Windows v9.0 (SPSS Inc, Chicago, IL). Categorical data were analysed by chi-square or Fisher's exact test where appropriate. MannWhitney $U$ was used for simple comparison of continuous data; data shown are median (interquartile range). Multiple linear regression was used posthoc to control for potential confounders of outcome measures associated with genotype. A probability of $p<0.05$ was considered statistically significant for examination of primary outcomes. Secondary analysis was performed to demonstrate any association between genotype, disability, and performance in subscales of the developmental tests. Adjustment for multiple comparison was made using the Bonferroni correction. A probability of $p<0.005$ was considered statistically significant for secondary (subscale) analysis.

\section{RESULTS}

IL-6 genotype and follow-up to 51/2 y were available in 113 Caucasian patients. The study group [gestation, $30 \mathrm{wk}$ (range, 22-32); birthweight, $1451 \mathrm{~g}$ (range, 670-2300); males, 68 (60\%). maternal age, 27 y (16-39)] (see also Table 1) was representative of the original APIP population (15): severe intraventricular hemorrhage (IVH) occurred in 18 out of $308(6 \%)$ patients in the APIP and in 7 patients in this study (6\%), all GG genotype; PVL was found in 21 out of $308(7 \%)$ patients in APIP and 12 out of 113 in this study group (10\%). Antenatal corticosteroid use was $18 \%$ in this cohort (21 out of 113).

Genotype frequencies, CC 1 (1\%), GC 9 (8\%), GG 103 (91\%), demonstrated Hardy-Weinberg equilibrium and were similar to UK population controls, suggesting no survival selection before enrolment (14). Median gestational age of infants with $\geq 1 \mathrm{C}$ allele was lower than the comparison group (GG genotype): 29 (27-30) wk gestation and 31 (29-32) wk, respectively. All other demographic and neonatal variables were similar (Table 1).

There was no difference in the incidence of cranial ultrasound abnormalities across genotype groups: severe IVH occurred in 0 of the carriers of the $\mathrm{C}$ allele and in $7(7 \%)$ of the GG genotype infants $(p=0.91)$, whereas WMD due to all PVL was observed in $1(10 \%)$ of those with a C allele and $11(11 \%)$ of those of GG genotype $(p=0.99)$ (Table 1$)$. Cystic PVL occurred in $1(10 \%)$ of those with the $\mathrm{C}$ allele compared with $4(4 \%)$ in $\mathrm{GG}$ infants and ventriculomegaly was found on $0(0 \%)$ and $7(7 \%)$ occasions, respectively. Two (20\%) of the infants with a $\mathrm{C}$ allele were born at $<27$ wk gestation compared with $7(7 \%)$ of those with GG genotype $(p=0.18)$. Both of the infants $<27$ wk carrying a $\mathrm{C}$

Table 1. Study group characteristics and genotype.

\begin{tabular}{lcc}
\hline & $\begin{array}{c}-572 \mathrm{C} \text { allele } \\
(n=10)\end{array}$ & $\begin{array}{c}-572 \mathrm{GG} \\
(n=103)\end{array}$ \\
\hline Male sex & $6(60 \%)$ & $62(60 \%)$ \\
Gestation (wk)* & $29(27-30)$ & $31(29-32)$ \\
Intrauterine growth restriction & $1(10 \%)$ & $9(10 \%)$ \\
5-min Apgar score $<6$ & $1(10 \%)$ & $9(9 \%)$ \\
Prelabor rupture of membranes & $2(20 \%)$ & $8(9 \%)$ \\
$\quad>24$ h & & $33(32 \%)$ \\
Septicemia & $4(40 \%)$ & $7(7 \%)$ \\
Severe intraventricular & $0(0 \%)$ & $11(11 \%)$ \\
$\quad$ hemorrhage & $1(10 \%)$ & $2(2 \%)$ \\
Periventricular leukomalacia & $0(0 \%)$ & $9(9 \%)$ \\
Oxygen dependence at 36 wk & $1(10 \%)$ & $52(51 \%)$ \\
Corticosteroids for chronic & & \\
$\quad$ lung disease & $8(80 \%)$ & $26(24-30)$ \\
Nonmanual parental & & $69(67 \%)$ \\
$\quad$ occupations & $27(27-29)$ & $43(42 \%)$ \\
Maternal age (y)* & $7(70 \%)$ & \\
Maternal car use & $5(50 \%)$ & $(35 \%)$ \\
Mother educated beyond 16 y & $5(50 \%)$ & \\
Developmental support & & \\
\hline
\end{tabular}

Numbers in parentheses indicate interquartile range.

Continuous data comparison is by Mann-Whitney U. $* p=0.33$. 
allele had normal cranial ultrasounds throughout their clinical course and neither were disabled. The Griffiths DQ and the GCA for the two infants born at $<27 \mathrm{wk}$ and carrying a $\mathrm{C}$ allele were (DQ) 99.8 and 94.8 and (GCA) 81.0 and 92.0. No child carrying a $\mathrm{C}$ allele had a DQ or a GCA $<70$, compared with 1 infant $(1 \%)$ of GG genotype who had a DQ of $<70$ and $3(3 \%)$ who had a $\mathrm{GCA}<70$.

The distributions of the developmental scales in this cohort were normal-Griffiths DQ: mean DQ, 101 (SD 11), median DQ, 101 (interquartile range, 94-110); GCA: mean GCA, 100 (SD 16), median GCA, 102 (interquartile range, 91-112); Movement ABC: mean summative score, 7 (SD 7), median summative score, 5 (interquartile range, 1-10). C allele carriage was associated with worse DQ at $2 \mathrm{y}$ and GCA at 51/2y but not worse motor performance (2 y locomotor subscale DQ and Movement ABC)-DQ: C allele, 92.4 (89.9-96.6) versus 102.4 (94.4-110.6) for those with GG genotype $(p=0.002)$; GCA: C allele, 88.0 (80.3-102.8) versus GG 103.0 (92.0112.0) $(p=0.037)$; Movement ABC summative score: $\mathrm{C}$ allele, $8.3(6.6-20.3)$ versus $4.0(1.0-9.5)(p=0.081)$ (Table 1).

Gestational age itself was not predictive $(p<0.05)$ of a worse performance in the Griffiths or BAS in APIP or in this cohort, despite such description elsewhere (23). However, such trends exist within the original APIP data [effect size on DQ: +0.6 for each week of gestation, $95 \%$ confidence interval (CI) -0.3 to $1.6, p=0.20$ )] or GCA (effect size on GCA: +1.0 for each week of gestation, $95 \% \mathrm{CI}-0.1$ to $2.1, p=0.07$ ). Multiple linear regression (controlling for genotype and gestation for these reasons) demonstrated only an association between the $\mathrm{C}$ allele and a lower DQ or GCA (effect size of C allele on Griffiths DQ: $-9.2,95 \%$ CI -16.8 to $-1.7, p=0.017$; effect size of C allele on GCA: $-10.6,95 \% \mathrm{CI}-21.2$ to -0.1 , $p=0.047$ ) but not gestational age (effect size on DQ: 0.0 for each week of gestation, $95 \% \mathrm{CI}-1.1$ to $1.0, p=0.97$; effect size on GCA: 0.5 for each week of gestation, $95 \%$ CI -1.0 to $2.0, p=0.55)$. In the infants born at $\leq 30 \mathrm{wk}$ gestation $[n=56$ (8 C allele, 48 GG genotype)], developmental scores tended to be lower in infants with a $\mathrm{C}$ allele-Griffiths DQ: C allele, 92.4 (89.4-95.5) versus 102.4 (95.9-110.6) for those with GG genotype ( $p=0.002)$; DQ adjusted for social variables (15): $\mathrm{C}$ allele, 93.3 (91.4-99.6) versus $\mathrm{GG}$ genotype 99.9 (94.8-105.0) ( $p=0.036)$; GCA: C allele, 96.0 (81.0-106.6) versus GG genotype $103.5(92.3-112.0)(p=0.22)$.

\section{DISCUSSION}

We have demonstrated an association between IL-6 -572 C allele carriage and worse cognitive development after preterm birth. The numbers of patients carrying the relatively rare $-572 \mathrm{C}$ allele was small (10) and further confirmatory studies are clearly required, as are haplotype analyses in larger cohorts (24).

The lack of association between $\mathrm{C}$ allele carriage and ultrasound changes consistent with cystic PVL and ventriculomegaly may be due to the rarity of the $\mathrm{C}$ allele and the small number of patients with ultrasonographic evidence of white matter injury. The resolution of cranial ultrasonography is clearly inadequate to define all white matter injury (25), of which perhaps $50 \%$ of very preterm infants suffer to some extent. It is possible, therefore, that the link between the IL-6 $-572 \mathrm{C}$ allele and worse developmental performance at 2 and $5.5 \mathrm{y}$ is due to IL-6-mediated white matter damage affecting subsequent gray matter development and its ongoing wiring into childhood (11). Certainly, preterm infants with MRI evidence of white matter injury have reduced cortical gray matter volume (12). The mechanisms that injure the developing gray matter are, however, poorly elucidated and the same mechanisms that injure the white matter may directly affect gray matter. Nothing is known about constitutive IL-6 gene expression or IL-6 gene expression in response to ischemic, infective, or inflammatory signals within different areas of the preterm brain. It is therefore possible that gray matter injury and impaired cognitive development may occur independently of white matter damage and that different responses may be mediated by different IL-6 promoter polymorphisms.

Despite the association between $\mathrm{C}$ allele carriage and worse DQ and GCA, we did not demonstrate a statistically significant link between genotype and motor performance in the BAS or in the locomotor subscale of the Griffiths scales. There was, however, a clear trend toward worse overall performance in the ABC movement tests among $\mathrm{C}$ allele carriers $(p=0.08)$, which requires further exploration.

We also found an association between $\mathrm{C}$ allele carriage and lower gestational age in this cohort. It is possible that the -572 $\mathrm{C}$ allele is a risk factor for preterm birth, as other polymorphisms of pro-inflammatory cytokine and signalling molecules are also associated with preterm delivery $(26,27)$. The greater degree of immaturity in those carrying a $\mathrm{C}$ allele does not appear to explain fully the impact upon cognitive outcome, however, as gestational age was not predictive of a lower DQ or GCA. Given the small numbers of patients within this cohort studied, the lack of association between gestational age and outcomes could be the result of a type 11 error. Thus, impaired cerebral development, or perhaps more correctly developmental performance, could also (or in addition) be driven by the $\mathrm{C}$ allele predisposing to preterm birth. However, the size of any effects of gestational age upon DQ and GCA appear to be small in comparison to that of genotype. Neither did CC $+\mathrm{CG}$ infants have more adverse risk factors than their GG counterparts (Table 1). Furthermore, none of those infants carrying the -572 $\mathrm{C}$ allele had severe IVH. Nor was there any difference in social or parental factors or developmental support (Table 2), and nor was this association driven by the poor performance of disabled infants carrying a $-572 \mathrm{C}$ allele (Table 2 ).

We have used a candidate gene association approach to investigate the role of IL-6 in cognitive development after premature birth. These data are consistent with IL-6 expression modulating cognitive development in the preterm infant. It is unlikely that basal IL-6 expression itself is responsible for this effect alone, but is due to the complex interactions of the many pro-inflammatory events to which the brain of a preterm infant is exposed, potentiated by an individual infant's proinflammatory response. This response may in turn be mediated by such polymorphism as the IL-6 $-572 \mathrm{G}$ to $\mathrm{C}$ substitution. Such environmental stimuli to IL-6 expression may include maternal infection, intrauterine infection, delivery mode, hypoxia, septicemia, and chronic lung disease $(6,7,9,10,28-33)$. Because of the small numbers of patients in this preliminary study, use of two-by-four tables to try to dissect the geneenvironment interactions, perhaps the gold standard for large epidemiologic genetic study (34), is not possible here. Because of the rarity of the $\mathrm{C}$ allele, the numbers of infants are necessarily small in this group, however, if robust, such find- 
Table 2. Comparison of genotypes and developmental outcomes.

\begin{tabular}{|c|c|c|c|}
\hline & $-572 \mathrm{C}$ allele $(n=10)$ & $-572 \mathrm{GG}(n=103)$ & $p$ \\
\hline Griffiths Developmental Quotient & $92.4(89.9-96.6)$ & $102.4(94.4-110.6)$ & 0.002 \\
\hline Griffiths DQ adjusted for social factors* & $95.9(91.7-100.4)$ & $100.9(96.7-104.8)$ & 0.026 \\
\hline \multicolumn{4}{|l|}{ Subscale } \\
\hline Personal-social & $99.5(94.2-109.5)$ & $103.6(97.5-116.9)$ & 0.14 \\
\hline Hearing-speech & $92.0(80.5-96.5)$ & $100.5(89.6-117.6)$ & 0.025 \\
\hline Eye-hand coordination & $87.8(85.4-92.2)$ & $96.0(97.5-103.9)$ & 0.005 \\
\hline General cognitive ability & $88.0(80.3-102.8)$ & $103.0(92.0-112.0)$ & 0.037 \\
\hline Verbal reasoning & $98.0(86.3-107.3)$ & $105.0(94.0-114.0)$ & 0.21 \\
\hline Pictoral reasoning & $90.0(80.5-113.3)$ & $101.0(92.0-112.0)$ & 0.12 \\
\hline Spacial reasoning & $85.0(77.0-95.0)$ & $100.0(93.0-107.0)$ & 0.013 \\
\hline Movement ABC (summative score) & $8.3(6.6-20.3)$ & $4.0(1.0-9.5)$ & 0.081 \\
\hline
\end{tabular}

Continuous data comparison is by Manner Whitney U.

Data given as median (interquartile range).

* (APIP, 15)

ings might contribute to risk analysis among preterm infants and suggest a potential role for antiinflammatory strategies in management of the preterm child (35).

Acknowledgment. The authors thank Dr. Linda Hunt, Senior Lecturer in Statistics, Institute of Child Health, University of Bristol, for statistical advice.

\section{REFERENCES}

1. Wood NS, Marlow N, Costeloe K, Gibson AT, Wilkinson A 2000 Neurologic and developmental disability after extremely preterm birth. EPICure Study Group. N Engl J Med 343:378-384

2. Botting N, Powls A, Cooke RW, Marlow N 1998 Cognitive and educational outcome of very-low-birthweight children in early adolescence. Dev Med Child Neurol 40:652-660

3. Saigal S, Hoult LA, Streiner DL, Stroskopf BL, Rosenbaum PL 2000 Schoo difficulties at adolescence in a regional cohort of children who were extremely low birth weight. Pediatrics 105:325-331

4. Huddy CL, Johnson A, Hope P 2001 Educational and behavioural problems in babies of 32-35 weeks gestation. Arch Dis Child Fetal Neonatal Ed 85·F23-F28

5. Ment LR, Vohr B, Allan W, Katz KH, Schneider KC, Westerveld M, Duncan CC, Makuch RW 2003 Change in cognitive function over time in very low-birth-weight infants. JAMA 289:705-711

6. Duggan PJ, Maalouf EF, Watts TL, Sullivan MH, Counsell SJ, Allsop J, Al-Nakib L, Rutherford MA, Battin M, Roberts I, Edwards AD 2001 Intrauterine T-cell activation and increased proinflammatory cytokine concentrations in preterm infants with cerebral lesions. Lancet 358:1699-1700

7. Fotopoulos S, Pavlou K, Skouteli H, Papassotiriou L, Lipsou N, Xanthou M 2001 Early markers of brain damage in premature low-birth-weight neonates who suffered from marked perinatal asphyxia and/or infection. Biol Neonate 79:213-218

8. Martin-Ancel A, Garcia-Alix A, Pascual-Salcedo D, Cabanas F, Valcarce M, Quero J 1997 Interleukin-6 in the cerebrospinal fluid after perinatal asphyxia is related to early and late neurological manifestations. Pediatrics 100:789-794

9. Yoon BH, Romero R, Yang SH, Jun JK, Kim IO, Choi JH, Syn HC 1996 Interleukin-6 concentrations in umbilical cord plasma are elevated in neonates with white matter lesions associated with periventricular leukomalacia. Am J Obstet Gynecol 174:1433-1440

10. Yoon BH, Jun JK, Romero R, Park KH, Gomex R, Choi JH, Kim IO 1997 Amniotic fluid inflammatory cytokines (interleukin-6, interleukin-1 beta, and tumor necrosis factor-a), neonatal brain white matter lesions and cerebral palsy. Am J Obstet Gynecol 177:19-26

11. Marin-Padilla M 1997 Developmental neuropathology and impact of perinatal brain damage. II: white matter lesions of the neocortex. J Neuropathol Exp Neuro 56:219-235

12. Inder TE, Huppi PS, Warfield S, Kikinis R, Zientara GP, Barnes PD, Jolesz F, Volpe JJ 1999 Periventricular white matter injury in the premature infant is followed by reduced cerebral cortical gray matter volume at term. Ann Neurol 46:755-760

13. Stewart AL, Rifkin L, Amess PN, Kirkbride V, Townsend JP, Miller DH, Lewis SW, Kingsley DP, Moseley IF, Foster O, Murray RM 1999 Brain structure and neurocognitive and behavioural function in adolescents who were born very preterm. Lancet 353:1653-1657

14. Brull DJ, Montgomery HE, Sanders J, Dhamrait S, Luong L Rumley A, Lowe GD Humphries SE 2001 Interleukin- 6 gene $-174 \mathrm{~g}>\mathrm{c}$ and $-572 \mathrm{~g}>\mathrm{c}$ promoter polymor- phisms are strong predictors of interleukin-6 levels after coronary artery bypass surgery. Arterioscler Thromb Vasc Biol 21:1458-1463

15. Investigators for the Avon Premature Infant Project 1998 Randomised trial of parental support for families with very preterm children. Arch Dis Child Fetal Neonatal Ed 79:F4-11

16. Griffiths R 1954 The Abilities of Babies. University of London Press, London, pp 1-213

17. Elliot CD, Murray DJ, Pearlson LS 1983 The British Ability Scales. NFER-Nelson Publishing, Windsor, 1-321

18. Henderson SE, Sugden DA 1992 Movement Assessment Battery for Children. The Psychological Corporation, Sidcup Kent, pp 1-290

19. Levene MI 1981 Measurement of growth of the lateral ventricles in preterm infants with real-time ultrasound. Arch Dis Child 56:900-904

20. Dubowitz LM, Bydder GM, Mushin J 1985 Developmental sequence of periventricular leukomalacia. Correlation of ultrasound, clinical and nuclear magnetic resonance functions. Arch Dis Child 60:349-355

21. Leviton A, Gilles F 1997 Ventriculomegaly, delayed myelination, white matter hypoplasia and "periventricular" leukomalacia: how are they related? Pediatr Neurol 15:127-136

22. Paneth N 1999 Classifying brain damage in preterm infants. J Pediatr 134:527-529

23. Bhutta AT, Cleves MA, Casey PH, Cradock MM, Anand KJ 2002 Cognitive and behavioural outcomes of school-aged children who were born preterm: a meta analysis. JAMA 288:728-737

24. Terry CF, Loukaci V, Green FR 2000 Cooperative influence of genetic polymorphisms on interleukin 6 transcriptional regulation. J Biol Chem 275:18138-18144

25. Inder TE, Anderson NJ, Spencer C, Wells S, Volpe JJ 2003 White matter injury in the premature infant: a comparison between serial cranial sonographic and MR findings at term. AJNR Am J Neuroradiol 24:805-809

26. Roberts AK, Monzon-Bordonaba F, Van Deerlin PG, Holder J, Macones GA, Morgan MA, Strauss JF 3rd, Parry S 1999 Association of polymorphism within the promoter of the tumor necrosis factor alpha gene with increased risk of preterm premature rupture of the fetal membranes. Am J Obstet Gynecol 180:1297-1302

27. Lorenz E, Hallman M, Marttila R, Haataja R, Schwartz DA 2002 Association between the Asp299Gly polymorphisms in the Toll-like receptor 4 and premature births in the Finnish population. Pediatr Res 52:373-376

28. Taniguchi T, Koido Y, Aiboshi J, Yamashita T, Suzaki S, Kurokawa A 1999. Change in the ratio of interleukin-6 to interleukin-10 predicts a poor outcome in patients with systemic inflammatory response syndrome. Crit Care Med 27:1262-1264

29. Kallman J, Ekholm L, Eriksson M, Malmstrom B, Schollin J 1999 Contribution of interleukin-6 in distinguishing between mild respiratory disease and neonatal sepsis in the newborn infant. Acta Paediatr 88:880-884

30. Martin-Ancel A, Garcia-Alix A, Pascual-Salcedo D, Cabanas F, Valcarce M, Quero J 1997 Interleukin-6 in the cerebrospinal fluid after perinatal asphyxia is related to early and late neurological manifestations. Pediatrics 100:789-794

31. Yoon BH, Jun JK, Romero R Park KH, Gomez R, Choi JH, Kim IO 1997. Amniotic fluid inflammatory cytokines (interleukin-6, interleukin-1 beta, and tumor necrosis factor-a), neonatal brain white matter lesions and cerebral palsy. Am J Obstet Gynecol 177:19-26

32. Kilpinen S, Hulkkonen S, Wang XY, Hurme M 2001 The promotor polymorphism of the interleukin-6 gene regulates interleukin-6 production in neonates but not adults. Eur Cytokine Netw 12:62-68

33. Yoon BH, Romero R, Kim KS, Park JS, Ki SH, Kim BI, Jun JK 1999 A systemic fetal inflammatory response and the development of bronchopulmonary dysplasia. Am J Obstet Gynecol 181:773-779

34. Botto LD, Khoury MJ 2001 Commentary: facing the challenge of gene- environment interaction: the two-by-four table and beyond. Am J Epid 153:1016-1020

35. Dammann O, Leviton A 2000 Brain damage in preterm newborns: biological response modification as a strategy to reduce disabilities. J Pediatr 136:433-438 